about vaccine efficacy and immunity can be answered quickly providing there is continued enthusiastic cooperation from paediatricians in BPSU studies such as the study of invasive $H$ influenzae type $\mathrm{b}$ infection in vaccinated children. *

These questions relating to $H$ influenzae type $\mathrm{b}$ vaccine serve to exemplify a more general issue. They highlight the importance of adequate audit of changes to public health policy (such as immunisation practices), rigorous attention to which might lessen or circumvent unnecessary controversy such as the recent precipitous withdrawal of two measles, mumps and rubella vaccines from routine supply which occurred in the UK.

*Cases should be notified by phone (day or night) to Dr M Slack, Haemophilus Reference Laboratory, John Radcliffe Hospital, Oxford (telephone 0865 220852). In the Republic of Ireland, cases should be notified to Dr J Fogarty, Hib Study, Western Health Board, Galway (telephone 091-23122)
We acknowledge the support of the Medical Research Fund of Children Nationwide for their support of the BPSU.

R BOOY

ER MOXON

Department of Paediatrics,

Fohn Radcliffe Hospital,

Headington,

Oxford OX3 9DU

1 Booy R, Moxon ER, Macfarlane JA, Mayon-White RT, Slack MPE. Efficacy of Haemophilus influenzae type $b$ conjugate vaccine in Oxford region. Lance 1992; ii: 847

2 Black SB, Shinefield HR, Fireman B, et al. Efficacy in infancy of oligosaccharide conjugate Haemophilus influenzae type b (HbOC) vaccine in a United States population of 61,080 children. Pediatr Infect Dis $\mathcal{F} 1991 ; 10: 97-104$.

3 Peltola H, Kilpi T, Anttila M. Rapid disappearance of Haemophilus influenzae type b meningitis after routine childhood immunisation with conjugate vaccines. Lancet 1992; ii: 592-4.

4 Ward J, Brenneman G, Letson GW, Heyward WL. Limited efficacy of Haemophilus influenzae type $b$ conjugate vaccine in Alaska native infants. NEngl f Med 1990; 323: 1393-401.

5 Department of Health. Immunisation against infectious disease. London: HMSO, 1992.

\title{
How to get drugs into the respiratory tract
}

Virtually any drug solution or suspension may be delivered to the respiratory tract as an aerosol. This opens a wide range of options for direct treatment of respiratory diseases and provides a port of entry for systemic drug treatment.

In childhood, drug doses have largely evolved empirically and aerosol delivery methods have been adapted from adult practice. However, problems are encountered in getting drugs into the respiratory tract of young children. These include compliance, anatomical and physiological variations due to age, problems with drug delivery, and drug delivery devices.

\section{Compliance}

Compliance with treatment is, and will probably remain, the main difficulty in getting aerosols into the airways of children. It is essential to ensure that the parents and child understand the need for treatment, and to give careful, patient, and repeated explanation of inhaler techniques with positive reinforcement.

\section{Anatomical and physiological problems}

Although the majority of young children nose breathe at rest, the mode of children's breathing under different circumstances is not known. Nasal breathing is associated with lower lung deposition of aerosolised drugs in adults, but little is known about this in children. The absence of nasal hair in the preadolescent and the fact that the infant's head is larger with respect to its body than in adulthood may make nasal breathing less of a problem than would be expected.

Young children usually breathe tidally when given aerosolised medications. This may reduce deposition of drug in the lung peripheries compared with that of older, compliant children who inhale deeply and slowly.

Recent work focusing on the amount of nebulised drug available for inhalation demonstrates that the quantity of nebulised aerosol inspired, which includes that deposited in the nose and upper airways, may be independent of the size of the child after 6 months of age. ${ }^{1}$ Infants younger than this have small tidal volumes and inspiratory flow rates, and therefore inspire aerosol directly from the nebuliser without entraining surrounding room air. As the child grows and tidal volume increases, a greater amount of surrounding air not containing aerosol is inspired (entrained air). Thus the concentration of aerosol per breath of an older child is less than that of the younger child. The total dose inhaled may be similar, but dose per kilogram will be much less in the older child. It has been suggested that, on the basis of these findings, aerosols should be administered on a weight corrected concentration basis for children aged more than 6 months.

Indeed the age related decline in airways responsiveness reported in recent studies might reflect failure to correct adequately the test dose for the child's size rather than a genuine physiological event. ${ }^{2}$ Many hospitals, however, use a standard dosage for all ages in the case of antiasthma drugs, such as sodium cromoglycate and $\beta_{2}$ agonists, where side effects are uncommon.

\section{Drug or delivery failure?}

It is now well recognised that the disappointing clinical effect of some aerosolised drugs may be simply due to inadequate amounts reaching the airways.

This is illustrated by the initial use of nebulised steroids in young asthmatics. Beclomethasone dipropionate, delivered by spacer devices or powered capsule, usually results in substantial symptomatic improvement in asthmatic children. ${ }^{3}$ However, when administered by nebulisation, clinical response was disappointing, and the value of nebulised steroids in young asthmatics was questioned. ${ }^{4}$ Beclomethasone dipropionate is nebulised as a suspension, due to its poor solubility. Steroid particles leaving the nebuliser are surrounded by a layer of fluid, increasing their size and explaining the poor clinical effect. For the same initial dose of beclomethasone dipropionate given by a spacer device a much greater amount (5-10 fold) of drug is contained in particles of less than five microns diameter, the size below which lung deposition is likely. ${ }^{5}$ As anticipated from these results, use of spacer devices with a facemask attachment to deliver steroid aerosols to very young children and infants has shown an excellent clinical response in many cases. ${ }^{6}$ 


\section{Drug delivery devices}

The amount of drug entering the lungs is critically dependent on the particle size distribution of aerosolised drug. Particles less than five microns in diameter are considered ideal for lung deposition, while larger particles tend to deposit in the upper airway. However, aerosolised drugs are marketed and trials undertaken with little information available to the clinician on drug output from various delivery devices.

Delivery devices are discussed briefly below. Choice of device is influenced by availability, age, compliance, and drug used. The most exciting development is the increasing use of spacer devices with facemask attachments to deliver drugs to young children.

\section{Spacer devices with or without a facemask}

For ease of delivery, and in the case of inhaled steroids more effective delivery than by the nebulised route, spacer devices with or without facemasks are becoming increasingly popular..$^{578}$ In some North American hospitals spacer devices have replaced nebulisers in the management of acute asthma (personal communication). However, the dose of drug administered can be affected by many factors, including deposition on the spacer walls, use of multiple actuations, time lag before inhalation, and spacer size.

When a spacer device is used the dose available for inhalation is often accepted to be that leaving the metered dose inhaler. However, if the drug is given through a spacer device before inhalation by the patient, a substantial amount will deposit on the walls of the device, reducing the total dose to the patient considerably. For instance, only $0.7 \mathrm{mg}$ of a $5 \mathrm{mg}$ dose of sodium cromoglycate is available for inhalation after actuation into a $750 \mathrm{ml}$ spacer device (unpublished results).

Many examples exist where prior knowledge of the actual drug output from the delivery device would alter interpretation of results. For instance, Ebden et al unfairly compared budesonide given by a spacer device with beclomethasone dipropionate given directly from a metered dose inhaler. ${ }^{9}$ More recently estimates of the inhaled steroid dose that would warrant endocrine assessment failed to take into account the varying output from different drug delivery devices. ${ }^{10}$

Multiple actuations of the metered dose inhaler before inhalation should be avoided as drug output per actuation may be considerably reduced. Drug available for inhalation (for example sodium cromoglycate, unpublished results) also decreases rapidly with time after actuation into a spacer. Size of spacer device will also have an effect dependent upon the size of the patient. A study of tidal breathing has shown that at low tidal volumes the high aerosol concentration in smaller spacer devices enhances drug available for inhalation, while at higher tidal volumes the amount of drug available may be greater from larger chambers. ${ }^{11}$

\section{Nebulisers}

Adult studies have shown that only about $10 \%$ of the inhaled dose reaches the lower airways. Popularity of nebulised drugs was gained by excellent clinical response to $\beta_{2}$ agonists where only an extremely small amount of drug is needed to cause bronchodilatation. ${ }^{12}$

Unfortunately, with other medication such as aerosolised steroids, knowledge of drug output is essential to ensure optimum treatment and to minimise side effects. A guide of output characteristics of various drugs from different nebuliser devices is awaited. The following examples illustrate how this simple information may help clinical practice:

Increasing the flow of gas through the nebuliser from four to eight litres per minute alters the rate of drug output, the gas volume in which it is distributed, the aerosol concentration, and the volume of aerosol available during the inspiratory phase. Importantly, the amount of drug contained in particles smaller than five microns (respirable particles) increases considerably..$^{13}$

Using certain nebulisers over $85 \%$ of sodium cromoglycate is released within five minutes of the start of nebulisation. Waiting for up to 10 minutes for the chamber to become dry results in little increase in drug dose. A shorter nebulisation time encourages compliance. ${ }^{15}$

A closely fitting mask increases drug delivery, as a mask just a couple of centimetres away from the face will result in a marked decrease (up to $85 \%$ ) in drug available for inhalation. This may result in a struggling child receiving little of the prescribed drug. ${ }^{14}$

\section{Metered dose inhalers}

It is becoming increasingly accepted that metered dose inhalers should be avoided in childhood, except when used with a spacer device. Good inhaler technique seen in clinic is often poorly reproduced outside.

The Autohaler, a breath actuated metered dose inhaler, has been shown to improve lung deposition in adults who have poor coordination with inhalation. While such devices may have a role in childhood asthma information as to their efficacy in young children is awaited.

\section{Powdered drug delivery}

Powdered drug delivery systems are easy to use and are less reliant on inhaler technique.

The two most popular devices are the Diskhaler (Allen and Hanburys) and the Turbohaler (Astra). In older children and adults these appear to deliver adequate therapeutic amounts of drug to the lower respiratory tract. Although extremely useful for delivering bronchodilators, delivery of inhaled steroids through these devices should probably be restricted to children requiring low doses (less than $400 \mu \mathrm{g}$ / day). Doses in excess of this should be given via a spacer device to reduce oropharangeal deposition and systemic absorption with possible side effects. ${ }^{16} 17$

\section{Drug delivery on intensive care}

Oral steroids have been used with somewhat limited success in the treatment of bronchopulmonary dysplasia, and they have been associated with significant side effects. Delivery of steroids in a much smaller dose directly to the airways is an attractive alternative and a number of recent studies have explored this possibility. Compared with direct instillation of the drug into the lung, delivery of aerosols appears to result in a much more homogeneous deposition. Metered dose aerosols may be used to deliver the drug via a spacer device either in line with the ventilator circuit, ${ }^{18}$ or by actuating the drug into a collapsible spacer device that can ventilate the patient and deliver the aerosol to the lungs at the same time. ${ }^{19}$ In addition, nebulised steroids using a ventilated lung model have been shown to give reasonable lung deposition, depending on the nebuliser used. ${ }^{18}$

\section{New therapeutic options}

The importance of determining optimal methods of drug delivery to the respiratory tract is highlighted by new therapeutic options in the treatment of cystic fibrosis all of which will be dependent on adequate deposition of drug throughout the lungs.

Human plasma $\alpha_{1}$-antitrypsin is being given in an 
attempt to reduce the destructive effects of neutrophil elastase, which is released in excess in cystic fibrosis patients. $^{20}$

The use of amiloride may improve hydration of airway secretions due to inhibition of sodium, and thus water, reabsorption by the respiratory epithelium..$^{21}$

Sputum viscosity, markedly increased by DNA released from leucocytes and other cells, can be decreased by deoxyribonuclease, which breaks DNA strands into smaller fragments. ${ }^{22}$

The physiological defect in cystic fibrosis cells can be corrected in vitro after the introduction of a single copy of the normal version of the gene. Direct transfer of recombinant DNA is inefficient, so genes must be introduced into airway epithelial cells using viral vectors or chemical methods such as cationic liposomes.

\section{What next?}

Before clinical trials of drugs given by aerosol, such as those mentioned for cystic fibrosis, laboratory and clinical evaluation of the optimum delivery method is necessary. This may enhance therapeutic effect, and avoid both misinterpretation of results and 'unnecessary' trials on patients.

\section{CHRISTOPHER O'CALLAGHAN}

Department of Child Health,

Leicester Royal Infirmary,

PO Box 65,

Leicester LE2 $7 L X$

1 Collis GG, Cole CH, Le Souef PN. Dilution of nebulised aerosols by air entrainment in children. Lancet 1990; 336: 341-3.

2 Le Souef PN. Validity of methods used to test airway responsiveness in children. Lancet 1992; 339: 1282-4.
3 Gleeson JGA, Price JF. Controlled trial of budesonide given by the nebuhaler in preschool children with asthma. $B M F$ 1988; 297 : $163-6$.

4 Webb MSC, Milner AD, Hiller EJ, Henry RL. Nebulised beclomethasone dipropionate suspension. Arch Dis Child 1986; 61: 1108-10.

5. O'Callaghan C. Particle size of beclomethasone diproprionate produced by two nebulisers and two spacer devices. Thorax 1990; 45: 109-11.

6 Bisgaard H, Munck SL, Nielsen JP, Petersen W, Ohisson SV. Inhaled budesonide for treatment of recurrent wheezing in early childhood. Lancet budesonide for treat

7 O'Callaghan C, Milner AD, Swarbrick A. Spacer device with face mask attachment for giving bronchodilators to infants with asthma. BMF 1989; 298: $160-1$.

8 Yuksel B, Greenough A, Maconochie I. Effective bronchodilator treatment by a simple spacer device for wheezy premature infants. Arch Dis Child.1990; 65: 782-5.

9 Ebden P, Jenkins A, Houston G, Davies BH. Comparison of two high dose corticosteroid aerosol treatments, beclomethasone diproporionate $(1500 \mu \mathrm{g})$ day) and budesonide (1600 ug/day), for chronic asthma. Thorax 1986; 41: 869-74.

10 Priftis K, Milner AD, Conway E, Honour JW. Adrenal function in asthma. Arch Dis Child 1990; 65: 838-40.

11 Everard ML, Clark AR, Milner AD. Drug delivery from holding chambers with attached face mask. Arch Dis Child 1992; 67:580-5.

12 Ruffin RE, Kenworthy MC, Newhouse MT. Response of asthmatic patients to fenoterol inhalation. A method of quantifying the airway bronchodilator dose. Clin Pharmacol Ther 1978; 23: 338-45.

13 Clay MM, Pavia D, Newman SP, Clark SW. Factors influencing the size distribution of aerosols from jet nebulisers. Thorax 1983; 38: 755-9.

14 Everard ML, Clark AR, Milner AD. Drug delivery from jet nebulisers. Arch Dis Child 1992; 67: 586-91.

15 O'Callaghan C, Clark AR, Milner AD. Why nebulise for more than 5 minutes? Arch Dis Child 1989; 64: 1270-3.

16 Farrer M, Francis AJ, Pearce SJ. Morning serum cortisol concentrations after $2 \mathrm{mg}$ inhaled beclomethasone dipropionate in normal subjects: effect of a 750 $2 \mathrm{mg}$ inhaled beclomethasone dipropionate

17 Brown PH, Blundell G, Greening AP, Crompton GK. Do large volume spacer devices reduce the systemic effects of high dose inhaled corticosteroids? Thorax 1990; 45: 736-9.

18 Grigg J, Arnon S, Jones T, Clarke A, Silverman M. Delivery of therapeutic aerosols to intubated babies. Arch Dis Child 1992; 67: 25-30.

19 O'Callaghan C, Hardy J, Stammers J, Stephenson TJ, Hull D. Evaluation of techniques for delivery of steroids to lungs of neonates using a rabbit model. Arch Dis Child 1992; 67: 20-4.

20 McElvaney NG, Hubbard RC, Birrer P. Aerosol alpha-1 antitrypsin treatment for cystic fibrosis. Lancet 1991; 337: 392-4.

21 Knowles MR, Church NL, Waltner WE. A pilot study of aerosolised amiloride for the treatment of cystic fibrosis. NEnglf Med 1990; 322: $1189-94$.

22 Shak S, Capon DJ, Hellmiss R, Marsters SA, Baker CL. Recombinant human DNasel reduces the viscosity of cystic fibrosis sputum. Proc Natl Acad Sci USA 1990; 87: 9188-92. 